\title{
Paths to improving care of Australian Aboriginal and Torres Strait Islander women following gestational diabetes
}

\author{
Sandra Campbell ${ }^{1,2}$, Nicolette Roux ${ }^{3}$, Cilla Preece ${ }^{4}$, Eileen Rafter ${ }^{3}$, Bronwyn Davis ${ }^{5}$, Jackie Mein ${ }^{2, a}$, \\ Jacqueline Boyle ${ }^{6}$, Bronwyn Fredericks ${ }^{7}$ and Catherine Chamberlain ${ }^{4, b}$ \\ ${ }^{1}$ Centre for Chronic Disease Prevention, James Cook University, Smithfield, QLD, Australia \\ ${ }^{2}$ Apunipima Cape York Health Council, Bungalow, QLD, Australia \\ ${ }^{3}$ Wuchopperen Health Service, Manoora, QLD, Australia \\ ${ }^{4}$ Indigenous Health Equity Unit, School of Population and Global Health, University of Melbourne, Carlton, VIC, Australia \\ ${ }^{5}$ School of Nursing, Midwifery \& Nutrition, James Cook University, Smithfield, \\ QLD, Australia \\ ${ }^{6}$ School of Public Health and Preventive Medicine, Monash Centre for Health Research and Implementation, Monash \\ University, Melbourne, VIC, Australia \\ ${ }^{7}$ Office of Indigenous Engagement, Central Queensland University, Rockhampton North, QLD, Australia
}

\begin{abstract}
Aim: To understand enablers and barriers influencing postpartum screening for type 2 diabetes following gestational diabetes in Australian Indigenous women and how screening might be improved. Background: Australian Indigenous women with gestational diabetes mellitus (GDM) are less likely than other Australian women to receive postpartum diabetes screening. This is despite a fourfold higher risk of developing type 2 diabetes within eight years postpartum. Methods: We conducted interviews with seven Indigenous women with previous GDM, focus groups with 20 Indigenous health workers and workshops with 24 other health professionals. Data collection included brainstorming, visualisation, sorting and prioritising activities. Data were analysed thematically using the Theoretical Domains Framework. Barriers are presented under the headings of 'capability', 'motivation' and 'opportunity'. Enabling strategies are presented under 'intervention' and 'policy' headings. Findings: Participants generated 28 enabling environmental, educational and incentive interventions, and service provision, communication, guideline, persuasive and fiscal policies to address barriers to screening and improve postpartum support for women. The highest priorities included providing holistic social support, culturally appropriate resources, improving Indigenous workforce involvement and establishing structured follow-up systems. Understanding Indigenous women's perspectives, developing strategies with health workers and action planning with other health professionals can generate context-relevant feasible strategies to improve postpartum care after GDM. Importantly, we need evidence which can demonstrate whether the strategies are effective.
\end{abstract}

Key words: Australian; gestational diabetes mellitus; Indigenous; postpartum screening

Received 16 February 2017; revised 19 April 2017; accepted 30 April 2017;

first published online 17 July 2017

Correspondence to: Sandra Campbell, Apunipima Cape York Health Council, 186 McCoombe Street, Bungalow, QLD 4870, Australia. Email: sandy.campbell@jcu.edu.au

${ }^{a}$ Wuchopperen Health Service, Manoora, QLD, Australia.

${ }^{\mathrm{b}}$ Judith Lumley Centre, LaTrobe University, Melbourne, VIC, Australia.

(c) Cambridge University Press 2017 


\section{Introduction}

Gestational diabetes mellitus (GDM) is defined as diabetes diagnosed during pregnancy [World Health Organization (WHO), 2013]; its prevalence is increasing across the globe (Ferrara, 2007). In addition to serious complications during pregnancy and birth [HAPO Study Cooperative Research Group (HAPO), 2008], GDM is associated with increased risk of developing type 2 diabetes (T2DM) following pregnancy, with mothers from Indigenous populations internationally particularly affected (Kim, 2002; Chamberlain et al., 2015c).

Recent evidence about GDM-associated risks has prompted revisions of international clinical management guidelines (Nankervis et al., 2013; WHO, 2013). Whilst changes that recommend earlier antenatal screening of 'at-risk' women are likely to offer benefits, it is also essential that, whenever population-based screening is introduced, acceptable and effective prevention, treatment and follow-up are provided (Australian Health Ministers' Advisory Council, 2008). There is little evidence that prevention, treatment and follow-up are being satisfactorily provided in screening programmes for GDM; this particularly applies to postpartum follow-up after GDM for Aboriginal Australians and Torres Strait Islanders (hereafter Indigenous) (Chamberlain et al., 2013). The prevalence of GDM is substantially higher in Australian Indigenous women compared with non-Indigenous women and this is coupled with steeper increases with higher maternal age. That makes early GDM detection and management in pregnancy and the postpartum period so much more important for T2DM prevention (Chamberlain et al., 2014).

Women at highest risk of subsequent T2DM are less likely to receive postpartum diabetes screening (Hunt and Conway, 2008). Previous data-linkage evaluation of existing postpartum care services for women in Far North Queensland found that Indigenous women with GDM had more than a fourfold risk of developing T2DM within eight years than other Australian women (Chamberlain et al., 2015c), and that 25\% developed T2DM within five years of their pregnancy. Postpartum diabetes screening rates were low for all women, but were significantly lower among Indigenous women compared with nonIndigenous women (Chamberlain et al., 2015b).
The lowest rates were among Indigenous women living in the regional centre (Cairns) compared with those living in remote areas (Chamberlain et al., 2015a).

Delayed diagnosis and treatment of T2DM leads to poor glucose control. This poses serious risks to subsequent pregnancies with congenital abnormalities (Farrell et al., 2002), macrosomia, caesarean section (HAPO, 2008), intra-uterine growth restriction (Ornoy, 2011), shoulder dystocia, neonatal hypoglycaemia and intensive care admissions (Aljohani et al., 2008; HAPO, 2008; Dyck et al., 2010). There are also risks for the infant in the long term: obesity, hyperglycaemia, T2DM and renal disease (Osgood et al., 2011). Indigenous women have higher parity (DeCosta and Child, 1996) and shorter pregnancy intervals than non-Indigenous women; thus, delays in postpartum screening potentially have greater consequences. Undiagnosed and untreated T2DM can have serious consequences for the mother, including heart disease, stroke, renal disease, limb amputation and blindness (Australian Institute of Health and Welfare, 2010).

Previous research has highlighted the frequency and characteristics of postpartum diabetes screening among Indigenous women (Chamberlain et al., 2015b), but the reasons for the low screening rates are not clearly understood. This is where qualitative research can contribute to better understanding (Anderson and Robins, 1998) and development of effective locally relevant strategies to improve postpartum care. Ideally, this process will identify causal factors, rather than focussing on behaviour, and build on existing intrinsic strengths such as family and community connections, culture and relationship with country.

The key research questions of this study are as follows: (1) what factors influence low rates of postpartum screening for T2DM for Indigenous women with GDM in Far North Queensland; what are the enablers and barriers, and (2) how might postpartum screening be improved?

\section{Methods}

The study was approved by the Far North Queensland Human Ethics Committee (reference number: HREC/14/QCH/95-928), with support from Wuchopperen Aboriginal Health Service, 
Cairns and Apunipima Cape York Health Council. The project was conducted by Indigenous researchers with expertise in community-based research, and directed by a project advisory group which included both Indigenous and nonIndigenous health professionals and researchers with potential roles in the implementation of strategies to improve postpartum screening after GDM.

\section{Study design}

We used semi-structured qualitative methods to address the key issues. Sequential steps were broadly based on 'intervention mapping' (Bartholomew et al., 1998) and adapted as described by Taylor et al. (2013). The process began with face-to-face interviews with Indigenous women with a history of GDM to assess barriers and enablers to screening. Second, focus groups with Indigenous health workers were conducted to develop matrices and programme ideas (barriers and enablers). Finally, we convened workshops involving other health professionals (nurses, midwives, doctors, diabetes educators) to refine the strategies developed in the first phase of the project. The aim was to develop approaches that could feasibly be adopted within day-to-day health service contexts. An additional series of brainstorming, visualisation, and sorting and prioritising exercises was employed to gather and organise a range of ideas similar to 'concept mapping' described by Ahmad et al. (2012).

\section{Study setting and participant recruitment}

The study was conducted in Cairns, Far North Queensland, in collaboration with two communitycontrolled organisations, Apunipima Cape York Health Council and Wuchopperen Health Service, plus the Cairns Diabetes Centre, a Queensland Health facility that provides specialist care to pregnant women with diabetes. Apunipima Cape York Health Council provides primary health services in 11 remote communities in the Cape York region whilst Wuchopperen Health Service provides services for Indigenous people living in or visiting Cairns. The region has a population of over 290000 of whom $2500(11.2 \%)$ are Aboriginal and/or Torres Strait Islander people (Queensland Government, 2013).
Indigenous women with previous GDM were recruited via health service staff and project flyers displayed in waiting areas at Wuchopperen Aboriginal Health Service. Staff had previously attended a 'meet and greet' with the research team to discuss the aims and important details of the project. An Indigenous researcher discussed the study with interested women and arranged interviews at a convenient time and location. Women received a $\$ 25$ gift voucher for participating and a further $\$ 25$ voucher when they reviewed their interview notes for respondent validation. Modest remuneration is customary in this type of research within the region and provides recognition that participant contributions are valued.

Health workers who attended focus groups and other health professionals in the final workshops were recruited via formal email invitation and word-of-mouth, organised by key contact people at Wuchopperen and Apunipima health services. Key contacts at the Cairns Diabetes Centre assisted in the final health professional workshops. Workshop invitees were asked to nominate additional health professionals that may have been omitted in the invitation process (snowballing effect).

\section{Data collection}

The image of a pregnant Indigenous woman at a 'gate' to a health service was developed as a visual tool to facilitate discussion with women about postpartum screening barriers and enablers. A third-person scenario of a woman 'Mary' with GDM was devised to minimise the intrusive nature of interviews and give women more control over the degree of personal information they wished to share. The issues raised by women that might help or prevent 'Mary' from attending the health service were recorded on sticky notes and placed on the image. Towards the end of their interview, participants were given five 'red dots' and asked to use them to prioritise the issues that they felt were the most important. Participants later validated notes taken during the interview process.

In preparation for health worker focus groups and the final workshops, key themes from the interviews with women were coded under the headings 'enablers' and 'barriers'. Two Indigenous researchers used broad headings from the Theoretical Domains Framework (Michie et al., 2011) including three main headings for barriers 
(capability, opportunity and motivation) and two for enablers (intervention and policy).

The themes raised by women were displayed in subsequent audio-recorded health worker focus groups that were jointly conducted with Indigenous researchers. They commenced with a reflection on the main themes from interviews with women, then focussed on identifying key goals and how these might be achieved. Health workers were given five 'red dots' and asked to prioritise the enabling strategies they felt were most important.

Before the final 'other health professionals' workshops, participants received a summary preliminary analysis from the interviews and health worker focus groups, including a table listing key themes and a description of some of the text underlying those themes. At the outset of the workshop, there was a brief discussion on the barriers and enablers identified by women and health workers. However, the main focus of the workshop was on prioritising enabling strategies and considering issues related to implementation or action planning. Participants were asked to nominate 10 priorities each and encouraged to discuss their rationale in an open and consensual process. Focus group and workshop transcripts were made available to participants for validation and they were invited to remove or edit comments.

\section{Data analysis}

Notes from interviews and focus group and workshop transcripts were entered into NVivo 10 (QSR International Pty Ltd, 2012) and coded for analysis. 'Nodes' were established using the Theoretical Domains Framework headings. Barrier nodes included 'capability' (physical knowledge, skills, memory and psychological behaviour); 'motivation' (automatic reinforcement, emotions, reflective role and identity, beliefs in capability and optimism, intention, goals and beliefs in consequences); and 'opportunity' (social influences or environmental context). Enabling nodes included 'interventions' (modelling, environmental restructuring, restrictions, education, persuasion, incentivisation, coercion, training, enablement) and 'policy' (fiscal measures, guidelines, environmental/social planning, communication/marketing, legislation, service provision, regulation). Content analysis was conducted and themes from the interview notes and focus group transcripts were coded under the abovementioned nodes and sent to the advisory group to check the accuracy of the coding. Summary tables were sent to focus group and workshop facilitators and participants to check that the analysis was consistent with discussions.

\section{Findings}

Characteristics of the study participants are detailed in Table 1. Interviews were conducted with seven Indigenous women who previously had GDM. They were recruited between February and July 2015. Five participated individually and two were interviewed together. Participants did not agree to audio recording and data were documented by hand during and immediately after each interview; notes were then validated by participants. Six of the women resided in Cairns, the region shown by our previous work to have the lowest rates of postpartum screening (Chamberlain et al., 2015a).

Health worker focus groups were held in July 2015 at Wuchopperen Health Service $(n=15)$ and Apunipima Cape York Health Council $(n=5)$. The participants were predominantly Indigenous health workers providing healthcare in Cairns and Cape York. Most participants were women, aged 25-45 years, and over half reported that they had been in their current role for more than two years.

A total of 24 participants attended 'other professionals' workshops held in October 2015 on two separate occasions at Apunipima Cape York Health Council. Workshop participants were predominantly female, non-Indigenous health professionals (doctors, nurses, midwives, diabetes educators) and half had been in their current role for two or more years.

\section{Perceived barriers to screening}

Content analysis of data collected in interviews with Indigenous women and focus groups with health workers identified a range of common themes. Barriers to women accessing appropriate postnatal follow-up after a pregnancy affected by GDM are presented under the Theoretical Domains Framework headings of 'capability', 'motivation' and 'opportunity', and summarised in Table 2. 
Table 1 Characteristics of study participants

\begin{tabular}{|c|c|c|}
\hline \multicolumn{3}{|c|}{$\begin{array}{l}\text { (a) Indigenous women with previous GDM participating } \\
\text { in interviews }(n=7)\end{array}$} \\
\hline \multicolumn{3}{|l|}{ Usual residence } \\
\hline Cairns & 6 & \\
\hline Remote & 1 & \\
\hline \multicolumn{3}{|l|}{ Age } \\
\hline$>35$ & 4 & \\
\hline $25-35$ & 2 & \\
\hline$<25$ & 1 & \\
\hline \multicolumn{3}{|l|}{ Parity } \\
\hline $5+$ & 2 & \\
\hline $2-4$ & 4 & \\
\hline 1 & 1 & \\
\hline \multicolumn{3}{|l|}{ Years since GDM } \\
\hline $5+$ & 4 & \\
\hline$<5$ & 3 & \\
\hline (b) & $\begin{array}{l}\text { Health worker } \\
\text { focus groups } \\
(n=20)\end{array}$ & $\begin{array}{l}\text { Health } \\
\text { professionals } \\
\text { workshops } \\
(n=24)\end{array}$ \\
\hline \multicolumn{3}{|l|}{ Aboriginal or Torres } \\
\hline \multicolumn{3}{|l|}{ Strait Islander } \\
\hline Yes & 16 & 5 \\
\hline No & 4 & 19 \\
\hline \multicolumn{3}{|l|}{ Gender } \\
\hline Female & 17 & 23 \\
\hline Male & 3 & 1 \\
\hline \multicolumn{3}{|l|}{ Age } \\
\hline$>45$ & 7 & 17 \\
\hline $25-45$ & 12 & 6 \\
\hline$<25$ & 1 & 1 \\
\hline \multicolumn{3}{|l|}{ Profession } \\
\hline Health worker & 13 & 1 \\
\hline Diabetes educator & 1 & 4 \\
\hline Nurse/midwife & 3 & 6 \\
\hline Doctor & 0 & 8 \\
\hline Other & 3 & 5 \\
\hline \multicolumn{3}{|c|}{ Years of current service } \\
\hline $5+$ & 7 & 7 \\
\hline $2-4$ & 5 & 5 \\
\hline$<2$ & 8 & 12 \\
\hline
\end{tabular}

GDM = gestational diabetes mellitus.

\section{Capability: physical and psychological}

Key physical factors associated with knowledge, skills and memory reported by Indigenous women, and possibly influencing low rates of postpartum diabetes screening included a lack of clear information, non-personalised information, and forgetting or receiving conflicting advice about GDM (Women 1, 5, 6 and 7). Health workers agreed and also described the problem of not knowing who has had GDM and 'lack of red flags' (clinician alerts) in patient electronic health records.

'So much conflicting advice, isn't there?'

(Health worker)

'They hear the same thing over and over and they don't get that information to them as an individual, it's that rhetoric they keep getting, and they get tired of that too' and 'you get that glazed look [from clients]. It's like what you're saying is going "wah, wah, wah"”.

(Health worker)

'The diabetes educator is good...but the two centres don't talk to each other'.

(Woman 6)

One woman described how no one had explained to her what GDM was, and that she was not provided with any information to read, however, she said, 'I was scared at first but found going to the doctor, that over time I was able to get some information and support' (Woman 1).

Psychological factors affecting health-seeking behaviours for postpartum screening identified by women and health workers ranged from fear and denial (Women 1 and 3), to accepting the inevitable development of T2DM and not understanding long-term risks, to simply being too tired and overwhelmed to access services.

'After a baby is born, life is stressful. With a new baby, mum gets no sleep and has no energy and... may be feeling overwhelmed'.

(Woman 3)

'I think another barrier is just generalised acceptance, I've got so many family members that have it, and not understanding that there's something they can necessarily do about it; so just that acceptance'.

(Health worker)

'I know, speaking to some clients I've had, they don't feel any different; they don't see that it's really a problem in the future, they're so focused on the here and now they can't even comprehend what might happen in the future. And because they feel ok, they don't see it necessarily as a problem'.

(Health worker) 
Table 2 Summary of barriers identified by women and health workers for accessing postnatal follow-up after gestational diabetes mellitus (GDM)

\begin{tabular}{|c|c|c|c|c|}
\hline Domain & Sub-domain & Theme & $\begin{array}{l}\text { Identified by } \\
\text { Indigenous women }\end{array}$ & $\begin{array}{l}\text { Identified by } \\
\text { health workers }\end{array}$ \\
\hline \multirow[t]{10}{*}{ Capability } & \multirow[t]{5}{*}{ Physical } & Conflicting advice & * & * \\
\hline & & Forgetting & * & \\
\hline & & Lack of information about GDM & * & \\
\hline & & $\begin{array}{l}\text { Health information unclear and inappropriate and } \\
\text { non-personalised information }\end{array}$ & * & * \\
\hline & & Not knowing who has had GDM & & * \\
\hline & \multirow[t]{5}{*}{ Psychological } & Accepting 'inevitability' of diabetes & * & * \\
\hline & & Denial of risk: 'does not apply to her' & & * \\
\hline & & Fear of diabetes or needles & * & * \\
\hline & & Not understanding risk & & * \\
\hline & & Tiredness & * & \\
\hline \multirow[t]{8}{*}{ Motivation } & \multirow[t]{4}{*}{ Automatic } & Shame & * & * \\
\hline & & 'Humbugging' & & * \\
\hline & & Stress & * & * \\
\hline & & Lack of motivation & * & \\
\hline & \multirow[t]{4}{*}{ Reflective } & Lack of belief in self & & * \\
\hline & & Feeling lack of control over choices & & * \\
\hline & & Putting self last & * & * \\
\hline & & Worry about baby & * & \\
\hline \multirow[t]{7}{*}{ Opportunity } & \multirow{4}{*}{$\begin{array}{l}\text { Environmental } \\
\text { context }\end{array}$} & Inconvenience and dislike of test & * & * \\
\hline & & Healthy food expensive & & * \\
\hline & & Lack of transport & * & \\
\hline & & $\begin{array}{l}\text { Limited resources, including limited } \\
\text { clinic hours }\end{array}$ & * & \\
\hline & \multirow{3}{*}{$\begin{array}{l}\text { Social } \\
\text { influence }\end{array}$} & Culturally unfriendly services & * & \\
\hline & & Lack of family support & * & \\
\hline & & Sorry business & * & \\
\hline
\end{tabular}

\section{Motivation: automatic and reflective}

Decision making in complex settings such as accessing health services involves both automatic emotional responses and more conscious reflective processes. The women and health workers reported emotional (automatic) responses relating to postpartum screening after GDM that included lack of motivation, shame, stress and 'humbugging. In this context, humbugging refers to a pressure situation where someone has repeated unwanted requests made of them.

'Could not be bothered', 'totally not motivated' and 'having a slack attack' were described as reasons for not attending postpartum screening.

(Woman 4)

'And sometimes when people find out, like if they were to come and get the test done and they've got diabetes or something, and then everyone at home finds out. Then everyone's on their back, and they want to avoid that kind of thing, that shame. They don't want everyone to know because then everyone will be criticising'.

(Health worker)

'A lot of people don't go because they know the professionals will be humbugging them all the time'.

(Health worker)

Reflective responses to accessing postpartum healthcare included lack of self-belief and control over choices.

'A lot of people feel they don't have a lot of control over their health. Because they feel they might not have that education and understanding, so they feel like they don't have control over it'.

(Health worker) 
'Sometimes they're not in control of the food that is at home too. They have limited say of what they do have to eat' and 'when you've got heaps of kids and you buy fruit and that, it just goes like no tomorrow'.

(Health worker)

Another barrier was women putting their own needs secondary to those of the family. One woman noted 'mum has to feel well within herself. Some mums put their health second to the wellbeing of their new baby' (Woman 3).

'There's consequences if you don't look after your kids. There's no consequences if you don't look after yourself' and 'Women in general always put people other than themselves first, but also at the end of the day there's bad things if you don't look after your kid...even if it's just the stigma in society. "Oh that mum's not looking after her kid" but there's no accountability for themselves'.

(Health worker)

\section{Opportunity: environmental and social influences}

Opportunities for self-care are regularly influenced by day-to-day life circumstances. The inconvenience and experience of the screening test, the perceived high cost of healthy food alternatives, and lack of transport and other resources were environmental factors identified as affecting postpartum screening and healthy lifestyle choices for Indigenous women after GDM.

Health workers pointed out that the oral glucose tolerance diagnostic test (OGTT) for T2DM ( $8 \mathrm{~h}$ fasting followed by a $75 \mathrm{~g}$ glucose drink and three venous blood tests over $2 \mathrm{~h}$ ) presents a substantial barrier to follow-up.

'The drink, a lot of people don't like it, so they won't come in for it. And the time it takes to have it as well' and 'Well, I guess it's the nature of the test really. If you just come in, have it done and go, that would be great'... 'ladies... probably put it off because they think "oh I've got to fast" or "I'll do it next week".

(Health worker)

Women described the inconvenience of travelling for the test and relying on public transport to attend appointments. For example, one woman described fasting and catching a 6am bus from her home to a major centre, returning at $5 \mathrm{pm}$. 'It was a long and tiring day and I was exhausted when I got back home' (Woman 1).

Health workers spoke about hospital dieticians recommending food items that were considered expensive and unsuitable. However, another health worker told the story of when

'We got a group of 10 or 15 girls together... and we made lentil soup. And on the evaluation form, most of the girl's feedback was "I found out today that soup is actually nice" and "I found out that you can actually eat lentils". So I think it is about that, having the same message but coming at it from different angles'.

(Health worker)

It was also reported however, that women 'sometimes don't have money' and 'having the facilities to cook too; whether [the stove] is working or not working' (Health worker).

Indigenous women identified a number of social factors as barriers to postnatal screening including unfriendly health services without Aboriginal or Torres Strait Islander staff (Women 1, 6 and 7), lack of support and stress at home from family (Women 1 and 2), and prioritising events such as sorry business associated with loss and grieving in the community (Woman 3).

\section{How might postpartum screening be improved?}

Project participants put forward 28 specific strategies for improving postpartum screening (Supplementary Table 3). In total, 10 of the 11 strategies identified by Indigenous women were reinforced by health workers and there was a high level of consensus among all study participants with regard to prioritisation; 16 of the 28 strategies received a priority rating by at least eight participants. They are presented under the Theoretical Domains Framework headings of 'interventions' and 'policies'.

\section{Interventions: environmental restructuring, education, persuasion and training}

The intervention strategy that received the highest priority by study participants was the need for 
environmental restructuring to holistically support and empower mothers and for this to be a community-led process (Priority no. 1):

'It's got to come from the community. We can go on until the cows come home, but if the community isn't behind it and giving the same message'.

(Health professional)

'It's how the social determinants of health all lead into this, like healthy food, prioritise for pregnant women, breastfeeding help, women with diabetes. Where as in some communities, the women have got no power, so they're the last to be prioritised with food and all that sort of stuff. So it's changing all those attitudes because the women have got no power'.

(Health professional)

Appropriate housing was raised as a critical issue for some women.

'I think support for housing in particular would be something I would like to see a lot more of. A lot of people are having housing crisis...if you haven't got a good place to live, you can't cook, you can't exercise; it's the last thing on your mind'.

(Health professional)

Suggestions for achieving better support and empowerment of mothers included starting early.

'It has to start before they have the child, at primary school. The empowerment for women before they make up their mind when they're fourteen, get them before then'.

(Health worker)

And when women become mothers, it is also important to not 'just talk about women as their role as a mother...even though they are a mum, it's important to try and look at themselves' (Health worker).

Indigenous health worker involvement in healthcare was viewed as valuable.

'Half the time they're going in and not understanding what's going on, so having a health worker beside them [helps]'.

(Health professional)
Other suggestions for ways to support mothers were as follows: providing young mothers support groups, flexible extended family support, counselling and social work support, and support in dealing with stress and 'emotional refuelling'.

The educational intervention given the highest priority for improving postpartum screening after GDM was development of culturally appropriate resources about GDM and health. Participants highlighted the importance of plain language and languages other than English to improve consistency of information from health professionals (Priority no. 2).

'I think we all know doctors can go around and say a lot of stuff, and they walk away, and they look like "what the hell did they say?"' and 'Yeah, because if you go in there and you don't speak English and you've got a white lady saying “blah blah blah”...I'd be running'.

(Health worker)

Suggestions included 'Maybe changing the wording, like fasting, fasting sounds so difficult. But in the pamphlet, say stop eating before 10 o'clock at night... it somehow makes it less dramatic'.

(Health worker)

Participants also proposed other educational interventions such as early school-based education about GDM and mass media and public health campaigns (Priority no. 5), and actively involving fathers and men's health teams in education (Priority no. 16).

Some put forward a strategy for a persuasive intervention to improve postpartum screening after GDM, encouraging Indigenous women to prioritise their own health needs; caring for their baby by caring for themselves. Women should be encouraged to ask questions and ask for help (Priority no. 8).

'...you cannot look after your child if you don't look after yourself'.

(Health worker)

When mothers bring their children for immunisations it was suggested that it was an ideal opportunity to enquire about their own welfare 
and needs. Health professionals thought this practice was often already informally in place, but it could be more structured.

'How are you coping, have you got any concerns, is there any domestic violence? All of the social and emotional wellbeing'.

(Health professional)

'I think it's happening. And I think as nurses and care givers we give it without realising. Because we wouldn't see a mother and not ask her about how she's going'.

(Health professional)

'So you embed that and make it routine into all your visits, you will get their thinking into "Oh it's ok for me to look after myself, make it a normal thing"'.

(Health professional)

A training intervention to improve knowledge about GDM among the diabetes workforce was another priority (Priority no. 10). Health workers wondered if more specific GDM training was required. 'Maybe to talk about gestational diabetes as an issue on its own?' (Health worker). Health professionals also acknowledged a need for GDM training for health workers.

'It's so complex for the Indigenous healthworker. I find it complex. Who do you see, when do you see them, who do you refer them to? There's no simple pathway. Look how confusing it is'.

(Health professional)

\section{Policy: communication, service provision, guidelines and fiscal}

Policies to increase Indigenous health staff in hospitals and clinics were seen as high priority for improving engagement and communication with Indigenous women with GDM (Priority no. 3). Such a strategy should include allied health staff and encompass improvements in collaboration, networking and support for Indigenous staff. Indigenous health workers play a key role in engaging women in prevention and participants emphasised the need for continuing to upgrade their skills.
'Having a support healthworker at the hospital would help a great deal, but new resources were limited in the Indigenous staffing area'.

(Health professional)

'I could probably put it down to the healthworker. Because your healthworker is the communication between all the supports they need, they always come back to your healthworker'.

(Health professional)

'I think we need to make sure they're appropriately trained and competent...I think it's important to have people who are quite skilled'.

(Health professional)

Priority no. 15 identified better provision of cultural training for non-Indigenous staff as a strategy to improve communication and trust between carers.

'There's a lack of trust between the nonIndigenous clinicians and the healthworkers. Whereas if there wasn't that, the nonIndigenous worker wouldn't have to be the one to give the messages. And that only comes from having more cultural awareness'.

(Health worker)

Participants considered that effective communication between the hospital and other health services was vital for improving postpartum screening with establishment of formal arrangements between services (Priority no. 12).

'I think when we start to have service agreements that things start working better. Anyone can have an MOU, but it's actually at the next level when services start sitting together, meeting, case conferencing'.

(Health worker)

The largest number of enabling strategies identified by women, health workers and health professionals involved service provision to improve postpartum screening. One participant noted that 'medical information from the Cairns hospital to my Wuchopperen GP could be improved. It's lacking in all areas' (Woman 5). Health workers prioritised having a co-ordinated and structured system with 'no gaps' for follow-up between locations and across time points (Priority no. 4). 
Care processes would benefit from co-ordination of reminders for women, improved 'diabetes in pregnancy' registers and effective flags in patient electronic medical records. Participants also flagged the introduction of more holistic continuity of care models (Priority no. 6) that offer home visiting and practical support (Priority no. 9), provision of better breastfeeding support during and after pregnancy (Priority no. 14), and ensuring flexibility in models of care that cater to the needs of women who have had GDM (Priority no. 13).

A recent change to clinical guidelines with an alternative to the OGTT was the point-of-care non-fasting $\mathrm{HbA} 1 \mathrm{c}$ test. This was welcomed by participants (Priority no. 7).

Another priority identified sustainable funding for service provision as a key fiscal policy. (Priority no. 11). Lack of funding was seen as a major source of frustration for providers, with programmes considered effective, frequently being cut. Participants described previous de-funded programmes that would have addressed current issues.

'All the time, our prevention, our health
promotion and prevention services, are the
things that get cut all the time. How can we get
to sustain them?'

(Health professional)

\section{Discussion}

This study provides an important perspective on the reasons behind low postpartum screening rates following a diagnosis of GDM in Indigenous women. They include limitations of physical capability (conflicting advice and lack of clear information, and forgetting) plus psychological and motivational barriers such as denial, fear, tiredness, shame, stress, worry, feelings that diabetes is inevitable and that women lack control over choices, lack of belief in themselves and putting their own health last. There were also environmental and social factors such as disliking the choice of tests, housing problems, lack of transport, lack of family support and culturally unfriendly health services. Participants highlighted difficulties of following up women in Cairns due to failure of health service systems. Importantly, participants proposed and refined a broad range of enabling interventions and policies that were culturally and demographically relevant, and achievable.
These findings were generated by and for the local community. This is not the first time some of these issues have been recognised; they have mostly been in other settings. We found several previously identified barriers to postpartum screening that were relevant to Indigenous women in Far North Queensland, including long travel distances to have an OGTT, and conflicting guideline-based advice about cardio-metabolic risk (Chamberlain et al., 2015a). We also found many identified barriers to screening similar to those described elsewhere (Bennett et al., 2011; Sterne et al., 2011) including lack of awareness and forgetting about the need for a test, test inconvenience, the unpleasant nature of the test and the fear of results, poor communication, time pressures, costs and lack of GDM documentation. A high 'perception of risk' coupled with low 'self-efficacy' was similarly reported in Native American women with GDM (Jones et al., 2012). Some findings from this study are reminiscent of the 'extended parallel process model' (Popova, 2012) in the context of postpartum T2DM screening. Further studies should include the investigation of the 'narrative of fear' and the psychological challenges that accompany a diagnosis of diabetes (Abdalla and Novis, 2014). Importantly, available evidence indicates that, in circumstances where an individual perceives their efficacy as low, threatening health risk messages can paradoxically promote avoidance, denial and outright rejection of the messages in response to the fear instilled by them (Witte et al., 2001).

Several proposed enabling strategies have also been previously reported. The inconvenience of the OGTT and development of alternative postpartum screening test options has been highlighted (Priority no. 7) and there is ongoing debate about the relative sensitivity of the $\mathrm{HbA} 1 \mathrm{c}$ test as an alternative (Claesson et al., 2015). Taylor and McDermott (2010) have highlighted the importance of health literacy in relation to diabetes in Far North Queensland (Priority no. 5), and this will be important in supporting women to make informed choices about their postpartum diabetes screening options. Reduced risks of T2DM associated with a healthy body weight and exclusive breastfeeding have already been demonstrated in this cohort (Chamberlain et al., 2015c) and Priority no. 14 identified the need for support. Importantly, several system-based strategies to improve 
postpartum screening (Priority no. 4) proposed by health workers and other health professionals have already been reported as effective (Carson et al., 2013). These are having a systematic process for follow-up including physician reminders (Keely, 2012; Vesco et al., 2012), proactive postpartum care plans (Gabbe et al., 2011), registers (Dannenbaum et al., 1999), clinical protocols, electronic records, patient reminders (Ko et al., 2013) and education for women during pregnancy (Stasenko et al., 2011).

The challenges we faced in identifying women with previous GDM highlight the need to address issues at a systems level. Similarly, most of the issues prioritised by women, health workers and health professionals cannot be addressed by health services alone, and will require collaboration with external funding and policy stakeholders. For example, the prioritisation of community-led, holistic (Priority no. 1), strength-based, familyfocussed strategies to address social determinants of health, aligns closely with the priorities of the National Aboriginal and Torres Strait Islander Health Plan (NATSIHP) (Australian Government, 2013). This approach is evidence based and was developed following extensive consultation. The aim is to guide strategies for 'closing the gap' and improving health equity in Australia, and requires widespread multi-sectoral action. Community-controlled health services are well placed to play a key role in enabling community decision making and deep engagement with the community, as well as generating positive context-relevant health promotion materials, and supportive policy and fiscal structures are required to underpin their role.

Improving communication was identified as a high priority (no. 3) and collaboration with and between Indigenous staff and aligns with the NATSHIP 'health enabler' of Indigenous workforce development. This is likely to require engagement with education, employment and training providers. Holistic models of care featuring continuity (no. 6), home visiting (no. 9) and greater involvement of men (no. 16) or transport assistance to a 'one-stop shop' (nos. 17 and 18) flexible enough to provide opportunistic postnatal screening (no. 13) will require multi-disciplinary collaboration within services and senior support to re-organise care models. Steps to reduce waiting times at hospitals (no. 23) and an option for childcare during appointments (no. 20) were proposals given lower priority, but are likely to require resource investments. Action planning activities for implementation include stakeholder consideration of which strategies are feasible within existing resources, and which strategies require external collaboration to work towards long-term goals.

This study used a qualitative approach to identify the needs of women with T2DM in pregnancy and prioritise proposed interventions. It was grounded in Indigenous women's perspectives, and generated by Indigenous health workers with rich tacit expertise in both community and health services. It also involved health professionals in crafting implementation strategies. These were the study's major strengths. Limitations included the challenges in recruiting Indigenous women with a history of GDM and recording their interviews with note taking instead of audio. That is why study notes were validated by the women to ensure they accurately reflected their perspectives. Some focus group and workshop discussions were timelimited because of the time constraints of health workers and health professionals. These research limitations reflect Indigenous agency (Rigney, 1997) and the reality of people's lives.

Several strategies to improve access to postpartum screening that were identified in this study are also likely to improve access to other aspects of diabetes care. This is important in the light of disparities of comprehensive care (Cass et al., 2003). Further research must address the psychological and motivational barriers to diabetes care for Indigenous women, including the role of fear and 'strengths-based' strategies. This research provides a strong foundation for developing an intervention to improve care for Indigenous women with GDM in north Queensland, aligned with initial 'intervention mapping' steps (Bartholomew et al., 1998). However, there is a need to continue the process to refine, implement and evaluate effective strategies to improve care for Indigenous women with GDM, including postpartum follow-up. Implementation and evaluation strategies should be 'co-designed' and participatory to ensure they are context relevant and flexible. Evidence-based interventions, and their scientific evaluation, should be grounded in these real-world experiences and perspectives of Indigenous women (Nilsen, 2015). 


\section{Conclusion}

There is an urgent need to improve postpartum screening among Indigenous women with GDM. Understanding women's perspectives is essential to development of context-relevant strategies; this includes identification of psychological and motivational barriers, enlisting health workers with a rich tacit expertise of community issues and health services, and conducting implementation planning with other health professionals. The process has identified numerous enablers, with a high priority given to those aligned with the NATSIHP strategies. Key issues are social determinants of health and increasing Indigenous health workforce capacity, development of culturally appropriate resources to support health literacy and structured systems for postpartum follow-up after GDM.

\section{Acknowledgements}

The authors sincerely thank the women, health workers and service providers who generously contributed their time to share their experiences and expertise. The authors are grateful for partnerships with Wuchopperen Health Service and Apunipima Cape York Health Council and for the assistance of their staff, particularly Ms Marion Norrie, Ms Bonnie Curtis, Ms Libbi Graetz and Ms Rachael Ham. The authors also thank Dr Cathy Vaughan for providing advice on use of visual imagery for increasing participation in the interviews.

\section{Financial Support}

This work was funded by a Research Translation Grant from Diabetes Queensland (100358) and by National Health \& Medical Research Council of Australia (S.C., grant no. 1071889; C.C., grant no. 1088813).

\section{Conflicts of Interest}

None.

\section{Supplementary material}

To view supplementary material for this article, please visit https://doi.org/10.1017/S14634 23617000305

Primary Health Care Research \& Development 2017; 18: 549-562

\section{References}

Abdalla, L. and Novis, A. 2014: Uh Oh! I have received an unexpected visitor: the visitor's name is chronic disease. A Brazilian family therapy approach. Australian and New Zealand Journal of Family Therapy 35, 100-4.

Ahmad, F., Mahmood, S., Pietkiewicz, I., McDonald, L. and Ginsburg, O. 2012: Concept mapping with South Asian immigrant women: barriers to mammography and solutions. Journal of Immigrant and Minority Health 14, 242-50.

Aljohani, N., Rempel, B., Ludwig, S., Morris, M., Cheang, M., Murray, R., Bruce, S. and Shen, G. 2008: Impact of diabetes on maternal-fetal outcomes in Manitoba: relationship with ethnic and environmental factors. Clinical and Investigative Medicine 31, E338-345.

Anderson, R. and Robins, L. 1998: How do we know? Reflections on qualitative research in diabetes. Diabetes Care 21, 1387-388.

Australian Government 2013: National Aboriginal and Torres Strait Islander health plan 2013-2023. Canberra: Department of Health and Ageing Commonwealth of Australia.

Australian Health Ministers' Advisory Council 2008: Population based screening framework, updated September 2016. Retrieved 14 February 2017 from http://www.cancerscreening. gov.au/internet/screening/publishing.nsf/Content/16AE0B052 4753EE9CA257CEE0000B5D7/\$File/Final\%20Population \%20Based \%20Screening \%20Framework\%202016.pdf.

Australian Institute of Health and Welfare 2010: Australia's health 2010. Canberra: AIHW.

Bartholomew, L., Parcel, G. and Kok, G. 1998: Intervention mapping: a process for developing theory and evidencebased health education programs. Health Education and Behaviour 25, 545-63.

Bennett, W., Ennen, C., Carrese, J., Hill-Briggs, F., Levine, D., Nicholson, W. and Clark, J. 2011: Barriers to and facilitators of postpartum follow-up care in women with recent gestational diabetes mellitus: a qualitative study. Journal of Women's Health 20, 239-45.

Carson, M., Frank, M. and Keely, E. 2013: Postpartum testing rates among women with a history of gestational diabetes: systematic review. Primary Care Diabetes 7, 177-86.

Cass, A., Cunningham, J., Snelling, P., Wang, Z. and Hoy, W. 2003: Renal transplantation for Indigenous Australians: identifying the barriers to equitable access. Ethnicity and Health 8, 111-19.

Chamberlain, C., Banks, E., Joshy, G., Diouf, I., Oats, J., Gubhaju, L. and Eades, S. 2014: Prevalence of gestational diabetes mellitus among Indigenous women and comparison with non-Indigenous Australian women: 1990-2009. Australian and New Zealand Journal of Obstetrics and Gynaecology 54, 433-40.

Chamberlain, C., Fredericks, B., McLean, A., Oldenburg, B., Mein, J. and Wolfe, R. 2015a: Associations with low rates of 
postpartum glucose screening after gestational diabetes among Indigenous and non-Indigenous Australian women. Australian and New Zealand Journal of Public Health 39, 69-76.

Chamberlain, C., McLean, A., Oats, J., Oldenburg, B., Eades, S., Sinha, A. and Wolfe, R. 2015b: Low rates of postpartum glucose screening among Indigenous and non-Indigenous women in Australia with gestational diabetes. Maternal and Child Health Journal 19, 651-63.

Chamberlain, C., McNamara, B., Williams, E., Yore, D., Oldenburg, B., Oats, J. and Eades, S. 2013: Diabetes in pregnancy among Indigenous women in Australia, Canada, New Zealand and the United States: a systematic review of the evidence for screening in early pregnancy. Diabetes/ Metabolism Research and Reviews 29, 241-56.

Chamberlain, C., Oldenburg, B., Wilson, A., Eades, S., O'Dea, K., Oats, J. and Wolfe, R. 2015c: Type 2 diabetes after gestational diabetes: greater than a fourfold risk among Indigenous compared to non-Indigenous Australian women. Diabetes/ Metabolism Research and Reviews 32, 217-27.

Claesson, R., Ekelund, M., Ignell, C. and Berntorp, K. 2015: Role of HbA1c in post-partum screening of women with gestational diabetes mellitus. Journal of Clinical \& Translational Endocrinology 2, 21-25.

Dannenbaum, D., Verronneau, J., Torrier, J., Smeja, H., Robinson, E., Dumont, C., Kovitch, I. and Webster, T. 1999: Comprehensive computerized diabetes registry. Serving the Cree of Eeyou Istchee (eastern James Bay). Canadian Family Physician 45, 364-70.

DeCosta, C. and Child, A. 1996: Pregnancy outcomes in urban Aboriginal women. Medical Journal of Australia 164, 523-26.

Dyck, R., Osgood, N., Lin, T., Gao, A. and Stang, M. 2010: Epidemiology of diabetes mellitus among First Nations and non-First Nations adults. Canadian Medical Association Journal 182, 249-56.

Farrell, T., Neale, L. and Cundy, T. 2002: Congenital anomalies in the offspring of women with type 1, type 2 and gestational diabetes. Diabetic Medicine 19, 322-26.

Ferrara, A. 2007: Increasing prevalence of gestational diabetes mellitus: a public health perspective. Diabetes Care 30, S141-146.

Gabbe, S., Landon, M., Warren-Boulton, E. and Fradkin, J. 2011: Promoting health after gestational diabetes: a National Diabetes Education Program call to action. Obstetrics and Gynecology 119, 171-76.

HAPO Study Cooperative Research Group (HAPO) 2008: Hyperglycaemia and adverse pregnancy outcomes. New England Journal of Medicine 358, 1991-2002.

Hunt, K. and Conway, D. 2008: Who returns for postpartum glucose screening following gestational diabetes mellitus? American Journal of Obstetrics and Gynecology 198, 404. e1-4.e6.

Jones, E., Appel, S., Eaves, Y., Moneyham, L., Oster, R. and Ovalle, F. 2012: Cardiometabolic risk, knowledge, risk perception, and self-efficacy among American Indian women with previous gestational diabetes. Journal of Obstetric, Gynecologic, and Neonatal Nursing 41, 246-57.

Keely, E. 2012: An opportunity not to be missed - how do we improve postpartum screening rates for women with gestational diabetes? Diabetes/Metabolism Research and Reviews 28, 312-16.

Kim, C. 2002: Gestational diabetes and the incidence of type 2 diabetes: a systematic review. Diabetes Care 25, 1862-868.

Ko, J., Dietz, P., Conrey, E., Rodgers, L., Shellhass, C., Farr, S. and Robbins, C. 2013: Strategies associated with higher postpartum glucose tolerance screening rates for gestational diabetes mellitus patients. Journal of Women's Health 22, 681-86.

Michie, S., van Stralen, M. and West, R. 2011: The behaviour change wheel: a new method for characterising and designing behaviour change interventions. Implementation Science 6, 42. https://doi.org/10.1186/1748-5908-6-42.

Nankervis, A., McIntyre, H., Moses, R., Ross, G., Callaway, L., Porter, C., Jeffries, W., Boorman, C., De Vries, B. and McElduff, A. 2013: Consensus guidelines for the testing and diagnosis of gestational diabetes in Australia. Retrieved 14 February 2017 from http://adips.org/downloads/2014A DIPSGDMGuidelinesV18.11.2014_000.pdf.

Nilsen, P. 2015: Making sense of implementation theories, models and frameworks. Implementation Science 10, 53-65.

Ornoy, A. 2011: Prenatal origin of obesity and their complications: gestational diabetes, maternal overweight and the paradoxical effects of fetal growth restriction and macrosomia. Reproductive Toxicology 32, 205-12.

Osgood, N., Dyck, R. and Grassmann, W. 2011: The inter- and intragenerational impact of gestational diabetes on the epidemic of type 2 diabetes. American Journal of Public Health 101, 173-79.

Popova, L. 2012: The extended parallel process model: illuminating the gaps in research. Health Education and Behavior 39, 455-73.

Queensland Government 2013: Queensland Government Statistician's Office population estimates by Indigenous status, 2013. Retrieved 14 February 2017 from http://www. qgso.qld.gov.au/subjects/demography/atsi-people/tables/ pop-est-indigenous-status/index.php.

Rigney, L. 1997: Internationalisation of an Indigenous anticolonial cultural critique of research methodologies: a guide to Indigenist research methodology and its principles. Journal for Native American Studies 14, 109-21.

Stasenko, M., Liddell, J., Cheng, Y., Sparks, T., Killion, M. and Caughey, A. 2011: Patient counseling increases postpartum follow-up in women with gestational diabetes mellitus. American Journal of Obstetrics and Gynecology 24, 522. e1-22.e6.

Sterne, V., Logan, T. and Palmer, M. 2011: Factors affecting attendance at postpartum diabetes screening in women with gestational diabetes mellitus. Practical Diabetes International 28, 64-68. 


\section{Sandra Campbell et al.}

Taylor, N., Sahota, P., Sargent, J., Barber, S., Lach, J., Louch, G. and Wright, J. 2013: Using intervention mapping to develop a culturally appropriate intervention to prevent childhood obesity: the HAPPY (Healthy and Active Parenting Programme for Early Years) study. International Journal of Behavioral Nutrition and Physical Activity $10,142$.

Taylor, S. and McDermott, R. 2010: What do we know about health literacy and diabetes care, and what does this mean for Aboriginal and Torres Strait Islander peoples with diabetes? Aboriginal and Islander Health Worker Journal $34,28-30$.
Vesco, K., Dietz, P., Bulkley, J., Bruce, C., Callaghan, W., England, L., Kimes, T., Bachman, D., Hartinger, K. and Hornbrook, M. 2012: A system-based intervention to improve postpartum diabetes screening among women with gestational diabetes. American Journal of Obstetrics and Gynecology 207, 283.e1-83.e6.

Witte, K., Meyer, G. and Martell, D. 2001: The extended parallel process model, in effective health risk messages. A stepby-step guide. Thousand Oaks, CA: Sage Publications.

World Health Organization 2013: Diagnostic criteria and classification of hyperglycaemia first detected in pregnancy. Geneva: WHO Press. 